\title{
Turismo Comunitario, Alternativa De Desarrollo Turístico Estudio De Caso: Estudio De Factibilidad Para La Implementación De Una Ruta De Turismo Comunitario De Las Comunidades Shuar Atahualpa, Shuar Nantip Y Waorani Ñoñeno Para El Cantón Francisco De Orellana, Provincia De Orellana
}

\author{
Carlos Renato Chávez Velásquez \\ Docente - Investigador \\ Escuela Superior Politécnica De Chimborazo - Ecuador \\ Ingeniera en Ecoturismo - Facultad de Recursos Naturales \\ Escuela Superior Politécnica De Chimborazo - Ecuador \\ Docente - Investigador, Carrera de Turismo, Departamento Ciencias de la vida \\ Universidad Estatal Amazónica De Pastaza- Ecuador \\ Tecnólogo en Construcciones Andinas - Escuela de Construcciones Andinas \\ Instituto Superior "Jatun Yachay Wasi” Colta - Ecuador

\section{Juan Hugo Rodríguez Guerra \\ Oscar Iván Granizo Paredes} \\ Docente - Investigador \\ Escuela Superior Politécnica De Chimborazo - Ecuador \\ Jessyca Consuelo Chiriguayo Vega \\ Ingeniera en Ecoturismo - Facultad de Recursos Naturales \\ Escuela Superior Politécnica De Chimborazo - Ecuador

\section{Edison Eduardo Ruiz Mármol} \\ Docente - Investigador, Carrera de Turismo, Departamento Ciencias de la vida \\ Universidad Estatal Amazónica De Pastaza- Ecuador

\section{Juan Carlos Carrasco Baquero} \\ Docente - Investigador \\ Escuela Superior Politécnica De Chimborazo - Ecuador
}

\section{doi: 10.19044/esj.2017.v13n8p200 URL:http://dx.doi.org/10.19044/esj.2017.v13n8p200}

\section{Abstract}

Ecuador is a diversified country with great potential for tourism. The diversity can be seen in the variety of natural and cultural attractions found in the four natural regions. Orellana province is an home of five different indigenous nationalities. Each of these nationalities has its own language, 
customs and traditions. The indigenous nationalities of Shuar, Kichwa, and Waorani are located in the Francisco de Orellana canton. This canton has important natural and cultural attractions, which makes the development of a community-based tourism project viable. The geographical location of the communities of Atahualpa, Nantip, and Ñoñeno makes it feasible to design a tourism route, which would help these communities to share their natural and cultural richness. These communities have had difficulties in structuring their resources in a technical way. Therefore, this study aims to integrate all the touristic attractions in order to advertise them to the public to achieve sustainability and increase their competitiveness in the market. In order to achieve this goal, a feasible study was carried out to implement a community-based tourism route. Based on the market study, it was determined that there is a high demand of national and international tourists who would like to visit a tourism route in this canton. Also, there is a high demand to visit the flora and fauna found in the Amazon region of Ecuador. Three touristic packages were developed, which bring together all the communities. As a result, it makes them more competitive in the area. In conclusion, the implementation of a community-based route that uses touristic packages, would allow the direct participation of the people in the communities, the sustainable use of natural and cultural resources, and a fair and equitable distribution of the income generated by the touristic activities.

Keywords: Feasibility study, tourism products, tourism potential

\section{Resumen}

El Ecuador es un país diverso con gran potencial turístico, expresado en la variedad de atractivos naturales y culturales que se encuentran ubicados en las cuatro regiones naturales. En la provincia de Orellana se encuentran asentadas 5 nacionalidades, las cuales tienen idiomas, costumbres y tradiciones propias. Dentro del cantón Francisco de Orellana se encuentran asentadas las nacionalidades Shuar, Kichwa y Waorani. Este cantón cuenta con importantes atractivos naturales y culturales, lo que hace viable el desarrollo del turismo comunitario en el mismo. La ubicación geográfica de las comunidades de Atahualpa, Nantip y Ñoñeno hace factible la creación de una ruta de turismo comunitario, lo que ayudaría a estas comunidades a dar a conocer su riqueza natural y cultural. Durante los últimos años estas comunidades han tenido dificultades para estructurar sus recursos de forma técnica. A través del presente estudio se pretende integrar los atractivos turísticos y ofertarlos para lograr un desarrollo sostenible e incrementar la competitividad en el mercado. Para cumplir con dicho propósito, se realizó el estudio de factibilidad para implementar una ruta de turismo comunitario. A 
partir del estudio de mercado se determinó que existe una amplia demanda nacional e internacional de personas a quienes les gustaría visitar una ruta de turismo en el cantón. Así mismo se entrelaza con el turismo de naturaleza propio de la región Amazónica del Ecuador. Se procedió a elaborar 3 paquetes turísticos que unifican a las comunidades y las hacen más competitivas en el ámbito de desarrollo turístico de la zona. En conclusión, la implantación de una ruta comunitaria, utilizando los paquetes turísticos, permitiría la participación directa de los habitantes, el uso sostenible de los recursos naturales y culturales, y una distribución justa y equitativa de los beneficios económicos obtenidos por dicha actividad.

Palabras claves: Turismo comunitario, estudio de factibilidad, productos turísticos, potencial turístico

\section{Introducción}

El turismo es el único reglón importante de la economía mundial que no está sujeto a pactos, convenios, aranceles o cuotas, se lo entorpece ocasionalmente con visados e impuestos, (Jaramillo, 2006, pág. 3), es considerado como la mayor industria de servicios en el mundo (Azevedo, 2007, pág. 32); es definido como el conjunto de relaciones y fenómenos producidos por el desplazamiento y permanencia de personas fuera de su entorno (Quesada, 2007, pág. 8), también como las actividades que realizan las personas durante sus desplazamientos y estancias en distintos lugares diferentes al de su entorno habitual, (Cobarcos, 2006), el turismo se plantea, opera y se vende en el presente y en el futuro con base en los datos que proporciona la ciencia de la estadística (Gurría, 2004, pág. 95) .

Según la Organización Mundial de Turismo las llegadas de turistas internacionales en el mundo crecieron un 4,7\% en el 2014 mismas que alcanzaron los 1138 millones. Además en febrero del 2015 los ecuatorianos que salieron al exterior ascienden a 106442 lo cual demuestra que hubo un incremento del $23 \%$ en relación a las salidas del mes de febrero del año anterior. En febrero del 2015 se registró un decrecimiento en llegadas de turistas extranjeros al Ecuador de $-3,95 \%$ con respecto a febrero del año anterior (Coordinación General de Estadistica e Investigación del Ministerio de Turismo del Ecuador, 2015, págs. 6-9).

Ecuador tiene el potencial para posesionarse como el país más mega diverso del planeta puesto que cuenta con la mayor biodiversidad por unidad de superficie, misma que se expresa a través de la variedad de atractivos naturales y culturales ubicados en sus cuatros mundos (PLANDETUR, 2020, pág. 12), además las nacionalidades indígenas, pueblos afro ecuatorianos y montubios representan el 21\% de la población total del país (ANINP, 20132017, pág. 7). Además de ser considerado como un país plurinacional, 
pluricultural con comunidades indígenas diferentes con sus propias lenguas y características culturales (Azevedo, 2007, pág. 64).

El turismo en el Ecuador ocupa la tercera posición en lo referente a exportaciones no petroleras. El ingreso de divisas por turismo de acuerdo con lo registrado en la balanza de pagos asciende a 1.251,2 millones durante el año 2013 lo que representa el 21\% en comparación con el 2012 (Coordinación General de Estadistica e Investigación del Ministerio de Turismo del Ecuador, 2015, págs. 9-11). Además en el plan nacional del buen vivir 2013-2017 consta que una de las metas a cumplir es el incrementar al 64,0\% los ingresos por turismo (SENPLADES, 2013-2017, pág. 309).

El buen vivir permite la permanencia de la diversidad cultural y ambiental bajo los términos de armonía, equidad y solidaridad; construyendo así una sociedad más justa donde el eje principal es el ser humano (SENPLADES, 2013-2017, págs. 14-22), además en la constitución reconoce el derecho a vivir en un ambiente sano, ecológicamente equilibrado que garantice la sostenibilidad y el buen vivir (Constitución de la República del Ecuador, 2008, pág. 13) .

El turismo comunitario forma parte de una estrategia de desarrollo local, como una forma de frenar la emigración desde las comunidades, se trata de una estrategia socio-económica de desarrollo comunitario, donde los beneficios deben repercutir sobre el conjunto de miembros según el grado de participación de los mismos, (Ruiz \& Solis, 2007, pág. 16). También es una modalidad que forma parte del turismo rural, puesto que se desarrolla en el medio rural a través de diferentes servicios turísticos pero con la especialidad de ser gestionado bajo modelos de gestión comunitaria, lo cual significa que las asambleas de las organizaciones locales o regionales son quienes toman las decisiones el cómo se reparten las utilidades de la actividad turística (Kekutt, 2014, pág. 55).

El turismo comunitario sostenible se entiende como una alternativa que, sin ser la panacea, puede contribuir a generar encadenamientos productivos y este modo reducir la presión sobre los recursos naturales (Ávila, y otros, 2002, pág. 119), además contribuye a conseguir un objetivo definido, como mejorar el bienestar de la comunidad, la calidad de vida y a mantener el patrimonio natural y cultural (Crosby, 2009, pág. 17).

El turismo comunitario en Ecuador es una actividad estratégica para muchas comunidades, misma que propicia el comercio en un entorno natural sostenible (Ruiz \& Solis, 2007, págs. 12-39). También el Ecuador es un estado de derecho en el que los procesos sociales se rigen por normas jurídicas, en el caso del turismo comunitario la construcción legal ha sido diferente, no ha nacido de la ley sino empezó como una actividad no 
reconocida que con esfuerzo y lucha llego a ser legalizada y reivindicada por varios actores sociales y políticos del país (Ruiz \& Solis, 2007, pág. 51)

La FEPTCE define al turismo comunitario como la relación de la comunidad con los visitantes desde una perspectiva intercultural en el desarrollo de viajes organizados, con la participación consensuada de sus miembros, garantizando el manejo adecuado de los recursos naturales, la valoración de sus patrimonios, los derechos culturales y territoriales de las nacionalidades y pueblos, para la distribución equitativa de los beneficios generados (Santana \& Atiencia, 2014, pág. 71). Además este tipo de turismo debe ser capaz de promover un desarrollo integral, mitigar la pobreza, generar empleos e ingresos económicos, evitando la migración de sus pobladores, fomentando una distribución justa de los ingresos (Kekutt, 2014, pág. 56).

La Ley de turismo en el art.-3 reconoce la iniciativa y participación comunitaria indígena, campesina, montubia o afro-ecuatoriana con su cultura $\mathrm{y}$ tradiciones preservando su identidad, protegiendo su ecosistema y participando en la prestación de servicios turísticos (Ley de turismo, 2008, pág. 1). En el art.-54 del Reglamento para los Centros de Turísticos Comunitario define al turismo comunitario como un modelo de gestión donde la comunidad aprovecha el patrimonio natural y cultural, desarrolla y ofrece un servicio turístico con la activa participación comunitaria para potenciar el desarrollo sostenible de la población mediante la reinversión de los beneficios derivados de la actividad turística (Reglamento para los Centros Turísticos Comunitarios, 2010, pág. 1). También se debe mencionar que el turismo no es la única fuente de generación de ingresos para las comunidades y que estas dependen de la articulación de productos complementarios en las cadenas de valor (MINTUR, 2011-2014, pág. 3).

La provincia de Orellana está ubicada en un punto estratégico de la amazonia ecuatoriana, rodeado de la selva tropical, paisajes fluviales además cuenta con presencia de 5 nacionales (waoranis, kichwas, shuar, tagaeris y taromennes) los dos últimos viven en aislamiento voluntario. Las comunidades Shuar Atahualpa, Shuar Nantip y Waorani Ñoñeno, se encuentran ubicadas en el cantón Francisco de Orellana poseen una variedad de recursos turísticos como son; cascadas, ríos, lagunas y bosques húmedos amazónicos, miradores naturales además de sus artesanías, gastronomía, costumbres, tradiciones, mitos y leyendas hacen factible el desarrollo del turismo comunitario utilizando sus recursos naturales y culturales de forma sostenible dejando como legado para las futuras generaciones. 


\section{Metodología}

En el presente estudio se aplicó técnicas de investigación bibliográfica (secundaria) y de campo (primaria), de manera explorativa, descriptiva y analítica; los cuales se detallan a continuación:

Para el inventario de los atractivos naturales de las comunidades de Atahualpa, Nantip y Ñoñeno se utilizó la metodología propuesta por el Ministerio de Turismo del Ecuador (MINTUR), 2004. En cuanto al registro de las manifestaciones culturales, se utilizó la metodología propuesta por el Instituto Nacional de Patrimonio Cultural (INPC), 2011.

\section{Evaluar el potencial turístico}

\section{Diagnóstico Situacional}

Se revisó y recopilo información mediante el análisis y sistematización de los planes de desarrollo cantonal, provincial y parroquial disponibles en el gobierno provincial, Asociación de Gobiernos Parroquiales e instituciones involucradas con este sector, complementándose con información primaria obtenida de entrevistas a los habitantes del sector. La información se sistematizó y ordeno acorde al diagnóstico estrella propuesto por Tierra (2012), en los siguientes ámbitos: físico espacial, socio cultural, ecológico territorial, económico productivo y socio cultural.

\section{Inventario de los atractivos turísticos}

Se realizaron salidas de campo en los cuales la herramienta que se utilizó es la ficha para inventariar atractivos turísticos propuesta por el MINTUR (2004), luego se procedió a georreferenciar, valorar, evaluar y jerarquizar cada atractivo.

En cuanto al inventario de recursos culturales se procedió a emplear la metodología propuesta por el Instituto Nacional de Patrimonio Cultural (INPC, 2011), utilizando las fichas de registro del patrimonio inmaterial de acuerdo a los parámetros establecidos en el "Instructivo para Fichas de Registro e Inventario del Patrimonio Cultural Inmaterial”. Consta de: a) Tradiciones y expresiones orales, b) Artes del espectáculo, c) Usos sociales, rituales y actos festivos, d) Conocimientos y usos relacionados con la naturaleza y el universo, e) Técnicas artesanales tradicionales.

\section{Para el análisis de la demanda se realizó Segmentación del mercado}

El segmento estuvo compuesto por los turistas nacionales y extranjeros que visitaron la provincia de Orellana en el año 2013. 


\section{Universo}

El universo de estudio según la segmentación de mercado es de 9880 de los cuales el 74\% (7311) son turistas extranjeros y el 26\% (2569) turistas nacionales (MINTUR, 2013).

\section{Muestra}

Para determinar la muestra se utilizó la formula estadística de Canavos 1998 con un margen de error del 5\%; del total de encuestas por medio de una regla de tres se distribuye la cantidad para los dos segmentos.

Dónde:

$$
n=\frac{(P * Q)(N)}{(N-1)(e / z)^{2}+P * Q}
$$

$\mathrm{n}=$ Tamaño de la muestra

$\mathrm{N}=$ Universo de estudio

$\mathrm{P}=0,5$ Probabilidad de ocurrencia de un evento

$\mathrm{Q}=0,5$ Probabilidad de no ocurrencia de un evento

$\mathrm{e}=5 \%$ Margen de error

$\mathrm{Z}=1,96 \%$ Nivel de confianza

$\mathrm{n}=$ muestra

$\mathrm{n}=\frac{9880 * 0.25}{(9880-1)(0.05 / 1.96)^{2}+0.25}$

$\mathrm{n}=370$

Se obtuvo como resultado un tamaño muestral de 370 encuestas, posteriormente se distribuyó de la siguiente manera; el $76 \%$ se multiplico por las 370 encuestas obteniendo como resultado 274 encuestas para internacionales y 96 encuestas a nacionales que representa el 26\%. Fueron aplicadas en la ciudad de Puerto Francisco de Orellana durante los meses de junio a septiembre del 2015.

\section{Análisis de la competencia}

Para definir la competencia se consideró los productos turísticos ofertados por las operadoras de turismo, con características similares al producto a implementarse.

\section{Proyección de la demanda potencial y competencia}

Con base a la demanda y competencia actual se realizó las proyecciones respectivas, para lo cual se utilizó el método del incremento compuesto, cuya fórmula es: $\mathrm{Co}=\mathrm{Cn}(1+\mathrm{i}) \mathrm{n}$ 


\section{Determinación de la demanda insatisfecha}

Se confronto la demanda potencial y competencia en base a una diferencia.

\section{Para el diseño del producto}

Para el diseño de la ruta se realizó la georreferenciación de las comunidades, se identificó y priorizo los sitios promisorios; Además para la elaboración de los paquetes se tomó como base al análisis de los atractivos, servicios e infraestructura existentes en la zona. También se identificó la planta turística necesaria para las actividades, así como las necesidades y requerimientos de las instalaciones.

\section{Resultados}

\section{Actualización del inventario de recursos naturales y manifestaciones culturales}

Tabla 1. Resumen de los atractivos naturales de las comunidades Atahualpa, Nantip y Ñoñeno

\begin{tabular}{|c|c|c|c|c|c|}
\hline \multirow{2}{*}{$\begin{array}{c}\text { Nombre del } \\
\text { atractivo }\end{array}$} & \multicolumn{3}{|c|}{ Clasificación } & \multirow{2}{*}{$\begin{array}{c}\text { Estado de } \\
\text { conservación }\end{array}$} & \multirow[t]{2}{*}{ JRQ } \\
\hline & Categoría & Tipo & Subtipo & & \\
\hline Kara Achite & Sitio natural & Ríos & Cascada & Conservado & II \\
\hline Río Cristal & Sitio Natural & Ríos & Riachuelo & Conservado & II \\
\hline $\begin{array}{l}\text { Kampuntín } \\
\text { comunitario }\end{array}$ & Sitio Natural & Bosques & $\begin{array}{c}\text { Bosque húmedo } \\
\text { amazónico }\end{array}$ & Alterado & II \\
\hline Río Tiguano & Sitio Natural & Ríos & Río & Conservado & II \\
\hline Río Saarentsa & Sitio Natural & Ríos & Riachuelo & Conservado & II \\
\hline $\begin{array}{l}\text { Laguna de } \\
\text { Ñoñeno }\end{array}$ & Sitio Natural & $\begin{array}{c}\text { Ambiente } \\
\text { lacustre }\end{array}$ & Laguna & Conservado & II \\
\hline Río Shiripuno & Sitio Natural & Ríos & Río & Conservado & II \\
\hline $\begin{array}{l}\text { Bosque húmedo } \\
\text { amazónico }\end{array}$ & Sitio Natural & Bosque & $\begin{array}{c}\text { Bosque húmedo } \\
\text { amazónico }\end{array}$ & Conservado & II \\
\hline
\end{tabular}

Tabla 2. Resumen de las manifestaciones culturales de las comunidades Atahualpa, Nantip y

\begin{tabular}{|c|c|c|c|}
\hline $\begin{array}{c}\text { Denominación de la } \\
\text { manifestación }\end{array}$ & Ámbito & Subámbito & Detalle del subámbito \\
\hline $\begin{array}{c}\text { Gastronomía típica de las } \\
\text { comunidades shuar y } \\
\text { waoranis }\end{array}$ & $\begin{array}{c}\text { Conocimientos y usos } \\
\text { relacionados con la } \\
\text { naturaleza y el } \\
\text { universo }\end{array}$ & Gastronomía & $\begin{array}{c}\text { Comidas y bebidas } \\
\text { típicas }\end{array}$ \\
\hline $\begin{array}{c}\text { Vestimenta típica de los } \\
\text { shuar y waoranis }\end{array}$ & $\begin{array}{c}\text { Técnicas artesanales } \\
\text { tradicionales }\end{array}$ & $\begin{array}{c}\text { Tejidos e } \\
\text { indumentaria }\end{array}$ & N/A \\
\hline $\begin{array}{c}\text { Leyendas el espíritu de la } \\
\text { yuca, NUNKUI creadora de } \\
\text { las plantas y Etza }\end{array}$ & $\begin{array}{c}\text { Tradiciones y } \\
\text { expresiones orales }\end{array}$ & leyendas & $\begin{array}{c}\text { Leyendas asociadas a } \\
\text { la aparición de seres } \\
\text { sobrenaturales }\end{array}$ \\
\hline $\begin{array}{c}\text { Música shuar 4 géneros } \\
\text { (anent, nampet, Ujaj y } \\
\text { Uwishin nampesma). }\end{array}$ & Artes del espectáculo & Música & Música \\
\hline $\begin{array}{c}\text { Danza shuar (Umachiru y } \\
\text { jantse). }\end{array}$ & Artes del espectáculo & Danza & Danza \\
\hline Música waorani 3 grupos de & Artes del espectáculo & Música & Música \\
\hline
\end{tabular}




\begin{tabular}{|c|c|c|c|}
\hline $\begin{array}{c}\text { expresiones musicales } \\
\text { (fiestas y eventos, ofrecidas } \\
\text { a los seres vivos u objetos y } \\
\text { las invocadas a la vida } \\
\text { cotidiana). }\end{array}$ & Artes del espectáculo & Danza & Danza \\
\hline $\begin{array}{c}\text { Danza waorani (bailes en } \\
\text { filas o entrelazados). }\end{array}$ & $\begin{array}{c}\text { Conocimientos y usos } \\
\text { relacionados con la } \\
\text { naturaleza y el } \\
\text { universo }\end{array}$ & $\begin{array}{c}\text { Medicina } \\
\text { tradicional }\end{array}$ & $\begin{array}{c}\text { Técnicas productivas y } \\
\text { sabiduría ecológica }\end{array}$ \\
\hline $\begin{array}{c}\text { Uso de plantas medicinales } \\
\text { festivos }\end{array}$ & $\begin{array}{c}\text { Usos sociales y actos } \\
\text { Chamanismo }\end{array}$ & Rituales & $\begin{array}{c}\text { Rituales asociados al } \\
\text { ciclo vital de grupos o } \\
\text { individuos }\end{array}$ \\
\hline Artesanías & $\begin{array}{c}\text { Técnicas artesanales } \\
\text { tradicionales }\end{array}$ & Artesanías & $\begin{array}{c}\text { Técnicas artesanales y } \\
\text { constructivas } \\
\text { tradicionales. }\end{array}$ \\
\hline
\end{tabular}

Fuente: Investigación de campo

\section{Análisis de la demanda}

\section{Género}

Tabla $N^{\circ}$ 1: Género de los potenciales clientes

\begin{tabular}{ccccc}
\hline & \multicolumn{2}{c}{ TURISTA NACIONAL } & \multicolumn{2}{c}{ TURISTA EXTRANJERO } \\
\hline VARIABLE & $\begin{array}{c}\text { FRECUENCIA } \\
\text { ABSOLUTA }\end{array}$ & $\begin{array}{c}\text { FRECUENCIA } \\
\text { RELATIVA }\end{array}$ & $\begin{array}{c}\text { FRECUENCIA } \\
\text { ABSOLUTA }\end{array}$ & $\begin{array}{c}\text { FRECUENCIA } \\
\text { RELATIVA }\end{array}$ \\
\hline Masculino & 59 & $61 \%$ & 159 & $58 \%$ \\
\hline Femenino & 37 & $39 \%$ & 115 & $42 \%$ \\
\hline Total & 96 & $100 \%$ & 274 & $100 \%$ \\
\hline
\end{tabular}

El 61\% de turistas nacionales son del género masculino, mientras que el 39\% del género femenino. Los turistas extranjeros con un 58\% del género masculino y el $42 \%$ del género femenino.

\section{Edad}

Tabla $\mathrm{N}^{\circ} 2$ : Edad de los potenciales clientes

\begin{tabular}{ccccc}
\hline & \multicolumn{2}{c}{ TURISTA NACIONAL } & \multicolumn{2}{c}{ TURISTA EXTRANJERO } \\
\hline VARIABLE & $\begin{array}{c}\text { FRECUENCIA } \\
\text { ABSOLUTA }\end{array}$ & $\begin{array}{c}\text { FRECUENCIA } \\
\text { RELATIVA }\end{array}$ & $\begin{array}{c}\text { FRECUENCIA } \\
\text { ABSOLUTA }\end{array}$ & $\begin{array}{c}\text { FRECUENCIA } \\
\text { RELATIVA }\end{array}$ \\
\hline $15-25$ años & 27 & $28 \%$ & 80 & $29 \%$ \\
\hline $26-45$ años & 56 & $58 \%$ & 102 & $37 \%$ \\
\hline $46-65$ años & 9 & $10 \%$ & 64 & $24 \%$ \\
\hline $66-75$ años & 4 & $4 \%$ & 28 & $10 \%$ \\
\hline Total & 96 & $100 \%$ & 274 & $100 \%$ \\
\hline
\end{tabular}

La edad de los turistas nacionales comprende entre 26 -45 años con un 58\%, seguido por el $28 \%$ que está entre los $15-25$ años, un $10 \%$ de $46-65$ años y un 4\% en el rango de 66-75 años. Mientras que los extranjeros el 37\% de $26-45$ años, el $29 \%$ de $15-25$ años, el $24 \%$ de $46-65$ años y el $10 \%$ de 66 75 años. 


\section{Estado civil}

Tabla $\mathrm{N}^{\circ}$ 3: Estado civil de los potenciales clientes

\begin{tabular}{ccccc}
\hline \multirow{2}{*}{ VARIABLE } & \multicolumn{2}{c}{ TURISTA NACIONAL } & \multicolumn{2}{c}{ TURISTA EXTRANJERO } \\
& ABSOLUTA & $\begin{array}{c}\text { FRECUENCIA } \\
\text { RELATIVA }\end{array}$ & $\begin{array}{c}\text { FRECUENCIA } \\
\text { ABSOLUTA }\end{array}$ & $\begin{array}{c}\text { FRECUENCIA } \\
\text { RELATIVA }\end{array}$ \\
\hline Soltera/a & 52 & $54 \%$ & 83 & $30 \%$ \\
\hline Unión libre & 24 & $25 \%$ & 61 & $22 \%$ \\
\hline Casado/a & 17 & $18 \%$ & 125 & $46 \%$ \\
\hline Divorciado/a & 3 & $3 \%$ & 5 & $2 \%$ \\
\hline Total & 96 & $100 \%$ & 274 & $100 \%$ \\
\hline
\end{tabular}

El estado civil de los turistas nacionales un 54\% son solteras/os, seguidos del 25\% que viven en unión libre, el 18\% casados y el 3\% de divorciados. Mientras que el $46 \%$ de los turistas extranjeros son casados, el $30 \%$ soltero, el 22\% viven en unión libre y el 2\% son divorciados.

\section{Procedencia}

Tabla $\mathrm{N}^{\circ}$ 4: Procedencia de los potenciales clientes

\begin{tabular}{cccccc}
\hline & \multicolumn{2}{c}{ TURISTA NACIONAL } & \multicolumn{3}{c}{ TURISTA EXTRANJERO } \\
\hline VARIABLE & $\begin{array}{c}\text { FRECUENCIA } \\
\text { ABSOLUTA }\end{array}$ & $\begin{array}{c}\text { FRECUENCIA } \\
\text { RELATIVA }\end{array}$ & VARIABLE & $\begin{array}{c}\text { FRECUENCIA } \\
\text { ABSOLUTA }\end{array}$ & $\begin{array}{c}\text { FRECUENCIA } \\
\text { RELATIVA }\end{array}$ \\
\hline Pichincha & 25 & $26 \%$ & $\begin{array}{c}\text { Estados } \\
\text { unidos }\end{array}$ & 91 & $33 \%$ \\
\hline Orellana & 15 & $16 \%$ & Colombia & 67 & $25 \%$ \\
\hline Chimborazo & 9 & $9 \%$ & Alemania & 61 & $22 \%$ \\
\hline Napo & 8 & $8 \%$ & Inglaterra & 16 & $6 \%$ \\
\hline Guayas & 7 & $7 \%$ & España & 8 & $3 \%$ \\
\hline Azuay & 7 & $7 \%$ & Argentina & 7 & $3 \%$ \\
\hline Tungurahua & 5 & $5 \%$ & Francia & 4 & $2 \%$ \\
\hline Sucumbíos & 4 & $4 \%$ & Chile & 5 & $2 \%$ \\
\hline El Oro & 4 & $4 \%$ & Perú & 4 & $1 \%$ \\
\hline Los Ríos & 3 & $3 \%$ & Uruguay & 3 & $1 \%$ \\
\hline Carchi & 3 & $3 \%$ & Venezuela & 3 & \\
\hline Santo & 2 & $2 \%$ & Canadá & 2 & $1 \%$ \\
Domingo & & & & & \\
Tsáchilas & 2 & $2 \%$ & Bolivia & 3 & \\
\hline Pastaza & 1 & $1 \%$ & Total & 274 & \\
\hline Manabí & 1 & $1 \%$ & & & \\
\hline Cañar & $100 \%$ & & & \\
\hline Total & 96 & &
\end{tabular}

El 26\% de los turistas nacionales proviene de Pichincha, el 16\% de Orellana, el 9\% Chimborazo, el 8\% del Napo, seguido del 7\% de Guayas y Azuay, un 5\% de Tungurahua, el 4\% de Sucumbíos, y el Oro, el 3\% de los Ríos y Carchi, un 2\% de Santo Domingo y Pastaza, seguido del 1\% de las provincias de Manabí y cañar. La procedencia de los turistas extranjeros es el 33\% de Estados Unidos, el 25\% de Colombia, el 22\% Alemania, el 6\% Inglaterra, el 3\% de España y Argentina, el 2\% de Francia, Chile y Perú, mientras que con el 1\% Venezuela, Uruguay, Canadá y Bolivia 


\section{Tamaño del grupo}

\begin{tabular}{ccccc}
\multicolumn{5}{c}{ Tabla N N $^{\circ}$ Acompañantes de los potenciales clientes } \\
\hline \multirow{2}{*}{ TURISTA NACIONAL } & \multicolumn{2}{c}{ TURISTA EXTRANJERO } \\
& $\begin{array}{c}\text { FRECUENCIA } \\
\text { ABSOLUTA }\end{array}$ & $\begin{array}{c}\text { FRECUENCIA } \\
\text { RELATIVA }\end{array}$ & $\begin{array}{c}\text { FRECUENCIA } \\
\text { ABSOLUTA }\end{array}$ & $\begin{array}{c}\text { FRECUENCIA } \\
\text { RELATIVA }\end{array}$ \\
\hline Solo & 56 & $58 \%$ & 22 & $8 \%$ \\
\hline Familiares & 21 & $22 \%$ & 73 & $26 \%$ \\
\hline Pareja & 15 & $16 \%$ & 95 & $35 \%$ \\
\hline Amigos & 4 & $4 \%$ & 84 & $31 \%$ \\
\hline Total & 96 & $100 \%$ & 274 & $100 \%$
\end{tabular}

El 58\% de los turistas nacionales organizan sus viajes solos, seguidos del $22 \%$ que viajan con sus familiares, el $16 \%$ en pareja, un $4 \%$ con amigos. Los turistas extranjeros con un 35\% viaja con su pareja, el 31\% con amigos, el $26 \%$ en familia y el $8 \%$ los organizan solos.

\section{Organización del viaje}

Tabla $\mathrm{N}^{\circ}$ 6: Forma de organización del viaje de los potenciales clientes

\begin{tabular}{ccccc}
\hline & \multicolumn{2}{c}{ TURISTA NACIONAL } & \multicolumn{2}{c}{ TURISTA EXTRANJERO } \\
\hline VARIABLE & $\begin{array}{c}\text { FRECUENCIA } \\
\text { ABSOLUTA }\end{array}$ & $\begin{array}{c}\text { FRECUENCIA } \\
\text { RELATIVA }\end{array}$ & $\begin{array}{c}\text { FRECUENCIA } \\
\text { ABSOLUTA }\end{array}$ & $\begin{array}{c}\text { FRECUENCIA } \\
\text { RELATIVA }\end{array}$ \\
\hline $\begin{array}{c}\text { De forma } \\
\text { independiente }\end{array}$ & 80 & $83 \%$ & 83 & $30 \%$ \\
\hline $\begin{array}{c}\text { Agencias de } \\
\text { viaje }\end{array}$ & 16 & $17 \%$ & 191 & $70 \%$ \\
\hline Total & 96 & $100 \%$ & 274 & $100 \%$ \\
\hline
\end{tabular}

El 83\% de los turistas nacionales viaja de forma independiente y el $17 \%$ con agencias de viaje. El $70 \%$ de los turistas extranjeros organiza sus viajes con las agencias de viaje y 30\% prefiere organizar de forma independiente.

\section{Motivo de viaje}

Tabla $N^{\circ} 7$ : Motivo de viaje de los potenciales clientes

\begin{tabular}{ccccc}
\hline & \multicolumn{2}{c}{ TURISTA NACIONAL } & \multicolumn{2}{c}{ TURISTA EXTRANJERO } \\
\hline VARIABLE & $\begin{array}{c}\text { FRECUENCIA } \\
\text { ABSOLUTA }\end{array}$ & $\begin{array}{c}\text { FRECUENCIA } \\
\text { RELATIVA }\end{array}$ & $\begin{array}{c}\text { FRECUENCIA } \\
\text { ABSOLUTA }\end{array}$ & $\begin{array}{c}\text { FRECUENCIA } \\
\text { RELATIVA }\end{array}$ \\
\hline Turismo & 43 & $45 \%$ & 171 & $62 \%$ \\
\hline Trabajo & 26 & $27 \%$ & 82 & $30 \%$ \\
\hline $\begin{array}{c}\text { Visita a } \\
\text { familiares }\end{array}$ & 15 & $16 \%$ & 15 & $6 \%$ \\
\hline Negocios & 7 & $7 \%$ & 3 & $1 \%$ \\
\hline Investigación & 3 & $3 \%$ & 2 & $1 \%$ \\
\hline Salud & 2 & $2 \%$ & 1 & $0 \%$ \\
\hline Total & 96 & $100 \%$ & 274 & $100 \%$ \\
\hline
\end{tabular}


El motivo principal por el cual viaja el turista nacional con un $45 \%$ es por turismo, el $27 \%$ por trabajo, el $16 \%$ por visita a familiares, el $7 \%$ por negocios, un $3 \%$ por investigación, además de un $2 \%$ por salud. El motivo del viaje de los turistas extranjeros con un $62 \%$ es por turismo, el $30 \%$ por trabajo, el $6 \%$ visita a familiares, el $1 \%$ por negocios e investigación y el $0 \%$ por salud.

\section{Temporada de viaje}

\begin{tabular}{ccccc}
\multicolumn{5}{c}{ Tabla No 8: Temporadas de viaje de los potenciales clientes } \\
\hline VARIABLE & $\begin{array}{c}\text { TRERISTA NACIONAL } \\
\text { ABSOLUTA }\end{array}$ & $\begin{array}{c}\text { FRECUENCIA } \\
\text { RELATIVA }\end{array}$ & $\begin{array}{c}\text { FRECUENCIA } \\
\text { ABSOLUTA }\end{array}$ & $\begin{array}{c}\text { FRECUENCIA } \\
\text { RELATIVA }\end{array}$ \\
\hline Feriados & 59 & $62 \%$ & 115 & $42 \%$ \\
\hline $\begin{array}{c}\text { Una vez al } \\
\text { año }\end{array}$ & 25 & $26 \%$ & 73 & $27 \%$ \\
\hline $\begin{array}{c}\text { Una vez al } \\
\text { mes }\end{array}$ & 9 & $9 \%$ & 55 & $20 \%$ \\
\hline Cada 15 días & 3 & $3 \%$ & 31 & $11 \%$ \\
\hline Total & 96 & $100 \%$ & 274 & $100 \%$ \\
\hline
\end{tabular}

Los turistas nacionales viajan con un $62 \%$ en feriados, el $26 \%$ una vez al año, el 9\% una vez al mes y un 3\% cada 15 días. El $42 \%$ de los turistas extranjeros realiza actividades turísticas en los feriados, mientras que el 27\% una vez al año, el 20\% una vez al mes y el 11\% cada 15 días.

\section{Conoce una ruta turística}

Tabla $N^{\circ}$ 9: Conocen una ruta turística los potenciales clientes

\begin{tabular}{ccccc}
\hline & \multicolumn{2}{c}{ TURISTA NACIONAL } & \multicolumn{2}{c}{ TURISTA EXTRANJERO } \\
\hline VARIABLE & $\begin{array}{c}\text { FRECUENCIA } \\
\text { ABSOLUTA }\end{array}$ & $\begin{array}{c}\text { FRECUENCIA } \\
\text { RELATIVA }\end{array}$ & $\begin{array}{c}\text { FRECUENCIA } \\
\text { ABSOLUTA }\end{array}$ & $\begin{array}{c}\text { FRECUENCIA } \\
\text { RELATIVA }\end{array}$ \\
\hline No & 96 & $100 \%$ & 274 & $100 \%$ \\
\hline $\mathrm{Si}$ & 0 & $0 \%$ & 0 & $0 \%$ \\
\hline Total & & $100 \%$ & & $100 \%$ \\
\hline
\end{tabular}

El $100 \%$ de los turistas nacionales y extranjeros no conoce una ruta turística en el cantón Francisco de Orellana.

\section{Visitaría una ruta de turismo comunitario}

Tabla $\mathrm{N}^{\circ}$ 10: Visitarían una ruta de turismo comunitario los potenciales clientes

\begin{tabular}{ccccc}
\hline & \multicolumn{2}{c}{ TURISTA NACIONAL } & \multicolumn{2}{c}{ TURISTA EXTRANJERO } \\
\hline VARIABLE & $\begin{array}{c}\text { FRECUENCIA } \\
\text { ABSOLUTA }\end{array}$ & $\begin{array}{c}\text { FRECUENCIA } \\
\text { RELATIVA }\end{array}$ & $\begin{array}{c}\text { FRECUENCIA } \\
\text { ABSOLUTA }\end{array}$ & $\begin{array}{c}\text { FRECUENCIA } \\
\text { RELATIVA }\end{array}$ \\
\hline $\mathrm{Si}$ & 71 & $74 \%$ & 217 & $79 \%$ \\
\hline No & 25 & $26 \%$ & 57 & $21 \%$ \\
\hline Total & 96 & $100 \%$ & 274 & $100 \%$ \\
\hline
\end{tabular}


El 74\% de los encuestados nacionales dieron a conocer que si visitarían una ruta de turismo comunitario y el $26 \%$ no visitaría. El $79 \%$ de los turistas extranjeros si visitarían una ruta turística comunitaria mientras que el $21 \%$ no visitaría

\section{Actividades turísticas}

Tabla $\mathrm{N}^{\circ}$ 11: Actividades turísticas preferidas por los potenciales clientes

\begin{tabular}{ccccc}
\hline & \multicolumn{2}{c}{ TURISTA NACIONAL } & \multicolumn{2}{c}{ TURISTA EXTRANJERO } \\
\hline VARIABLE & $\begin{array}{c}\text { FRECUENCIA } \\
\text { ABSOLUTA }\end{array}$ & $\begin{array}{c}\text { FRECUENCIA } \\
\text { RELATIVA }\end{array}$ & $\begin{array}{c}\text { FRECUENCIA } \\
\text { ABSOLUTA }\end{array}$ & $\begin{array}{c}\text { FRECUENCIA } \\
\text { RELATIVA }\end{array}$ \\
\hline $\begin{array}{c}\text { Observación } \\
\text { de flora y } \\
\text { fauna }\end{array}$ & 37 & $39 \%$ & 117 & $43 \%$ \\
\hline $\begin{array}{c}\text { Medicina } \\
\text { natural }\end{array}$ & 19 & $20 \%$ & 79 & $29 \%$ \\
\hline Danzas & 12 & $13 \%$ & 19 & $7 \%$ \\
\hline Convivencia & 11 & $11 \%$ & 43 & $16 \%$ \\
\hline Chamanismo & 9 & $9 \%$ & 9 & $3 \%$ \\
\hline $\begin{array}{c}\text { Compra de } \\
\text { artesanías }\end{array}$ & 8 & $8 \%$ & 7 & $100 \%$ \\
\hline Total & 96 & $100 \%$ & & \\
\hline
\end{tabular}

Las actividades que les gustaría realizar a los turistas nacionales en las comunidades con un 39\% observación de flora y fauna, el $20 \%$ plantas medicinales, un $13 \%$ danzas, el $11 \%$ convivencia, el $9 \%$ chamanismo y un 8\% la compra de artesanías. A los encuestados extranjeros con el 43\% observación de flora y fauna, el $29 \%$ actividades que estén vinculadas a la medicina natural, el 16\% convivencia, el 7\% danzas, el 3\% chamanismo y el 2\% compra de artesanías.

\section{Preferencias en alimentación}

Tabla $N^{\circ}$ 12: Alimentación que prefieren los potenciales clientes

\begin{tabular}{ccccc}
\hline & \multicolumn{2}{c}{ TURISTA NACIONAL } & \multicolumn{2}{c}{ TURISTA EXTRANJERO } \\
\hline VARIABLE & $\begin{array}{c}\text { FRECUENCIA } \\
\text { ABSOLUTA }\end{array}$ & $\begin{array}{c}\text { FRECUENCIA } \\
\text { RELATIVA }\end{array}$ & $\begin{array}{c}\text { FRECUENCIA } \\
\text { ABSOLUTA }\end{array}$ & $\begin{array}{c}\text { FRECUENCIA } \\
\text { RELATIVA }\end{array}$ \\
\hline Típica & 67 & $70 \%$ & 168 & $61 \%$ \\
\hline Nacional & 26 & $27 \%$ & 81 & $30 \%$ \\
\hline Vegetariana & 2 & $2 \%$ & 10 & $4 \%$ \\
\hline Internacional & 1 & $1 \%$ & 15 & $5 \%$ \\
\hline Total & 96 & $100 \%$ & 274 & $100 \%$ \\
\hline
\end{tabular}

El tipo de alimentación que prefieren los encuestados nacionales con un $70 \%$ es típica, el $27 \%$ nacional, el $2 \%$ vegetariana y un $1 \%$ internacional. El 61\% de los turistas extranjeros prefiere comida típica, el 30\% nacional, el $5 \%$ internacional y un $4 \%$ vegetariana. 


\section{Servicios turísticos demandados}

Tabla $\mathrm{N}^{\circ}$ 13: Servicios turísticos demandados por los potenciales clientes

\begin{tabular}{ccccc}
\hline & \multicolumn{2}{c}{ TURISTA NACIONAL } & \multicolumn{2}{c}{ TURISTA EXTRANJERO } \\
\hline VARIABLE & $\begin{array}{c}\text { FRECUENCIA } \\
\text { ABSOLUTA }\end{array}$ & $\begin{array}{c}\text { FRECUENCIA } \\
\text { RELATIVA }\end{array}$ & $\begin{array}{c}\text { FRECUENCIA } \\
\text { ABSOLUTA }\end{array}$ & $\begin{array}{c}\text { FRECUENCIA } \\
\text { RELATIVA }\end{array}$ \\
\hline Alimentación & 41 & $43 \%$ & 101 & $37 \%$ \\
\hline Transporte & 33 & $34 \%$ & 92 & $34 \%$ \\
\hline Guianza & 16 & $17 \%$ & 70 & $25 \%$ \\
\hline Hospedaje & 6 & $6 \%$ & 11 & $4 \%$ \\
\hline Total & 96 & $100 \%$ & 274 & $100 \%$ \\
\hline
\end{tabular}

Los servicios con los que le gustaría contar al turista nacional con un $43 \%$ es el de alimentación, el $34 \%$ con transporte, el $17 \%$ con guianza y al $6 \%$ con hospedaje. A los encuestados extranjeros con el $37 \%$ es de alimentación, el 34\% transporte, el 25\% guianza y un 4\% hospedaje.

Estimación de gasto promedio diario

Tabla $N^{\circ}$ 14: estimación de gasto promedio diario de los potenciales clientes

\begin{tabular}{ccccc}
\hline & \multicolumn{2}{c}{ TURISTA NACIONAL } & \multicolumn{2}{c}{ TURISTA EXTRANJERO } \\
\hline VARIABLE & $\begin{array}{c}\text { FRECUENCIA } \\
\text { ABSOLUTA }\end{array}$ & $\begin{array}{c}\text { FRECUENCIA } \\
\text { RELATIVA }\end{array}$ & $\begin{array}{c}\text { FRECUENCIA } \\
\text { ABSOLUTA }\end{array}$ & $\begin{array}{c}\text { FRECUENCIA } \\
\text { RELATIVA }\end{array}$ \\
\hline $\begin{array}{c}100-150 \\
\text { dólares }\end{array}$ & 56 & $58 \%$ & 43 & $16 \%$ \\
\hline $\begin{array}{c}150-200 \\
\text { dólares }\end{array}$ & 27 & $28 \%$ & 74 & $27 \%$ \\
\hline $\begin{array}{c}200-250 \\
\text { dólares }\end{array}$ & 12 & $13 \%$ & 132 & $48 \%$ \\
\hline $\begin{array}{c}250-300 \\
\text { dólares }\end{array}$ & 1 & $1 \%$ & 25 & $9 \%$ \\
\hline Total & 96 & $100 \%$ & 274 & $100 \%$ \\
\hline
\end{tabular}

Los turistas nacionales están dispuestos a gastar por día el 58\% de 100-150 dólares, un 28\% de 150-200 dólares, el 13\% de 200-250 dólares y el 1\% de 250-300 dólares. La disposición de gasto de los turistas extranjeros por día con el $48 \%$ de $200-250$ dólares, el $27 \%$ de 150 a 200 dólares, el $16 \%$ de 100-150 dólares, un 9\% de 250-300 dólares.

\section{Medio de información}

Tabla $\mathrm{N}^{\circ}$ 15: Medio de información utilizada por los potenciales clientes

\begin{tabular}{ccccc}
\hline & \multicolumn{2}{c}{ TURISTA NACIONAL } & \multicolumn{2}{c}{ TURISTA EXTRANJERO } \\
\hline VARIABLE & $\begin{array}{c}\text { FRECUENCIA } \\
\text { ABSOLUTA }\end{array}$ & $\begin{array}{c}\text { FRECUENCIA } \\
\text { RELATIVA }\end{array}$ & $\begin{array}{c}\text { FRECUENCIA } \\
\text { ABSOLUTA }\end{array}$ & $\begin{array}{c}\text { FRECUENCIA } \\
\text { RELATIVA }\end{array}$ \\
\hline Internet & 63 & $66 \%$ & 152 & $56 \%$ \\
\hline Amigos/Familiares & 27 & $28 \%$ & 39 & $14 \%$ \\
\hline Guías/Folletos & 5 & $5 \%$ & 83 & $30 \%$ \\
\hline TV Local & 1 & $1 \%$ & 0 & $0 \%$ \\
\hline Total & 96 & $100 \%$ & 274 & $100 \%$ \\
\hline
\end{tabular}


De acuerdo con los datos obtenidos los turistas nacionales buscan información sobre lugares turísticos con un 66\% en internet, el $28 \%$ amigos/familiares, el 5\% guías/ folletos, y el 1\% por la Tv local. Los medios que utilizan los turistas extranjeros para informarse sobre lugares turísticos con un $56 \%$ el internet, un $30 \%$ guías/folletos, el $14 \%$ por amigos/ familiares y el $0 \%$ Tv local.

\section{Análisis de la competencia}

Para determinar la oferta sustitutiva se ha considerado los productos turísticos comunitarios que son ofertados por las operadoras de turismo del cantón Francisco de Orellana, cabe mencionar que estas operan con atractivos turísticos del cantón Francisco de Orellana, La Joya de los Sachas y Aguarico, satisfaciendo así la demanda turística nacional e internacional. 
Tabla Nº16: Análisis de los productos turísticos ofertados por las operadoras de turismo del cantón Francisco de Orellana

\begin{tabular}{|c|c|c|c|c|c|c|}
\hline Operadora & Tour & $\begin{array}{c}\text { Productos } \\
\text { ofertados }\end{array}$ & $\begin{array}{l}\text { Modalidad } \\
\text { de turismo }\end{array}$ & Actividad & Atractivo & Comercialización \\
\hline \multirow{4}{*}{$\begin{array}{l}\text { WITOTO CÍA. } \\
\text { LTDA TOUR }\end{array}$} & $\begin{array}{l}\text { Comunidad } \\
\text { Indillama, } \\
\text { Limoncocha } \\
\text { Nuevo } \\
\text { Rocafuerte }\end{array}$ & $\begin{array}{l}\text { Grupo } \\
\text { étnico } \\
\text { quichua. }\end{array}$ & $\begin{array}{l}\text { Ecoturismo } \\
\text { y Turismo } \\
\text { comunitario }\end{array}$ & $\begin{array}{l}\text { Observación de la flora y fauna. } \\
\text { Recorrido en canoa. } \\
\text { Senderos autoguiados. } \\
\text { Caminatas nocturnas. } \\
\text { Observación de delfín rosado. } \\
\text { Convivencia } \\
\end{array}$ & $\begin{array}{l}\text { Laguna de Pañacocha } \\
\text { Laguna Jatuncocha. } \\
\text { Parque Nacional } \\
\text { Yasuni. } \\
\text { Museo CICAME }\end{array}$ & $\begin{array}{c}\text { Paquetes organizados } \\
\text { por operadoras. } \\
\text { Paquetes de } 3 \text { días y } 2 \\
\text { noches. } \\
\text { Costo } \$ 360 \text { por pax. }\end{array}$ \\
\hline & $\begin{array}{c}\text { Napo } \\
\text { Wildlife } \\
\text { Center }\end{array}$ & $\begin{array}{l}\text { Grupo } \\
\text { étnico } \\
\text { quichua. }\end{array}$ & $\begin{array}{l}\text { Ecoturismo } \\
\text { y Turismo } \\
\text { comunitario }\end{array}$ & $\begin{array}{c}\text { Recorrido por el sendero. } \\
\text { Visita la saladero de loros } \\
\text { Recorrido en canoa en la laguna } \\
\text { Añangu. }\end{array}$ & $\begin{array}{c}\text { Grupo étnico. } \\
\text { Laguna de Limoncocha. } \\
\text { Lodge Añango. } \\
\text { Saladero de loros } \\
\text { Añango. }\end{array}$ & $\begin{array}{c}\text { Paquetes organizados } \\
\text { por operadoras. } \\
\text { Paquetes de } 3 \text { días y } 2 \\
\text { noches. } \\
\text { Costo } \$ 360 \text { por pax. }\end{array}$ \\
\hline & $\begin{array}{l}\text { Circuito } \\
\text { turístico por } \\
\text { los tres ríos }\end{array}$ & $\begin{array}{c}\text { Recorrido } \\
\text { Fluvial }\end{array}$ & $\begin{array}{l}\text { Turismo de } \\
\text { aventura. }\end{array}$ & $\begin{array}{l}\text { Navegación por los tres ríos Napo, } \\
\text { Coca y Payamino. } \\
\text { Visita al Ecoparque Payamino. } \\
\text { Observación de plantas medicinales. }\end{array}$ & $\begin{array}{c}\text { Río Napo } \\
\text { Río Coca } \\
\text { Río Payamino } \\
\text { Ecoparque } \\
\text { Payamino } \\
\end{array}$ & $\begin{array}{l}\text { Paquetes organizados } \\
\text { por operadoras. } \\
\text { Tiempo de recorrido } \\
1 \text { h30 minutos. } \\
\text { Costo } \$ 50 \text { de } 1 \text { a } 5 \text { pax. }\end{array}$ \\
\hline & $\begin{array}{l}\text { Comunidad } \\
\text { Ñoñeno, } \\
\text { Bameno, } \\
\text { Cononaco. }\end{array}$ & $\begin{array}{l}\text { Grupo } \\
\text { étnico } \\
\text { Waorani }\end{array}$ & $\begin{array}{l}\text { Turismo } \\
\text { comunitario } \\
\text { y de } \\
\text { aventura. }\end{array}$ & $\begin{array}{c}\text { Convivencia } \\
\text { Actividades culturales. } \\
\text { Recorrido en canoa. } \\
\text { Senderos autoguiados. } \\
\text { Recorridos en canoa. } \\
\text { Natación. } \\
\text { Observación de aves. } \\
\end{array}$ & $\begin{array}{l}\text { Grupo étnico Waorani. } \\
\text { Río Shiripuno. } \\
\text { Laguna de Ñoñeno. }\end{array}$ & $\begin{array}{l}\text { Paquetes organizados } \\
\text { por operadoras. } \\
\text { Paquete de } 6 \text { días y } 5 \\
\text { noches. } \\
\text { Costo } \$ 780 \text { por pax. }\end{array}$ \\
\hline \multirow[t]{2}{*}{$\begin{array}{c}\text { SUMAKALLPA } \\
\text { TOUR }\end{array}$} & $\begin{array}{l}\text { Isla de los } \\
\text { monos }\end{array}$ & $\begin{array}{l}\text { Naturaleza } \\
\text { y cultura }\end{array}$ & $\begin{array}{l}\text { Turismo de } \\
\text { naturaleza y } \\
\text { Turismo } \\
\text { comunitario }\end{array}$ & $\begin{array}{l}\text { Senderos autoguiados. } \\
\text { Observación de la flora y fauna. } \\
\text { Avistamientos de monos. } \\
\text { Caminatas nocturnas. } \\
\text { Actividades culturales. }\end{array}$ & Isla de los monos. & $\begin{array}{l}\text { Paquetes organizados } \\
\text { por operadoras. } \\
\text { Duración: medio día. } \\
\text { Costo } \$ 80 \text { un pax, } \$ 90 \\
\text { por } 2 \text { pax y } \$ 120 \text { por } 6 \\
\text { pax. }\end{array}$ \\
\hline & $\begin{array}{l}\text { Isla de los } \\
\text { monos- } \\
\text { Reserva }\end{array}$ & $\begin{array}{l}\text { Naturaleza } \\
\text { y cultura }\end{array}$ & $\begin{array}{l}\text { Turismo de } \\
\text { naturaleza y } \\
\text { Turismo }\end{array}$ & $\begin{array}{l}\text { Senderos autoguiados. } \\
\text { Observación de la flora y fauna. } \\
\text { Avistamientos de monos. }\end{array}$ & $\begin{array}{c}\text { Isla de los monos. } \\
\text { Laguna de Limoncocha. }\end{array}$ & $\begin{array}{l}\text { Paquetes organizados } \\
\text { por operadoras. } \\
\text { Duración: } 3 \text { días y } 2\end{array}$ \\
\hline
\end{tabular}




\begin{tabular}{|c|c|c|c|c|c|c|}
\hline & $\begin{array}{c}\text { biológica } \\
\text { Limoncocha }\end{array}$ & & Comunitario & $\begin{array}{l}\text { Actividades culturales. } \\
\text { Caminatas nocturnas. } \\
\text { Recorrido en canoa }\end{array}$ & Río napo. & $\begin{array}{c}\text { noches. } \\
\text { Costo } \$ 270 \text { por pax. }\end{array}$ \\
\hline & $\begin{array}{l}\text { Ruta de los } \\
\text { waoranis }\end{array}$ & $\begin{array}{c}\text { Grupo } \\
\text { étnico } \\
\text { waorani }\end{array}$ & $\begin{array}{c}\text { Turismo } \\
\text { comunitario }\end{array}$ & $\begin{array}{c}\text { Senderos autoguiados. } \\
\text { Observación de la flora y fauna. } \\
\text { Actividades culturales. } \\
\text { Recorrido por los saladeros. } \\
\text { Recorrido por canoa. } \\
\text { Caminatas nocutrnas. }\end{array}$ & $\begin{array}{c}\text { Río Shiripuno. } \\
\text { Laguna de Ñoñeno } \\
\text { Comunidad Ñoñeno } \\
\text { Comunidad Bameno. } \\
\text { Saladeros de animales. }\end{array}$ & $\begin{array}{l}\text { Paquetes organizados } \\
\text { por operadoras. } \\
\text { Duración: } 6 \text { días y } 5 \\
\text { noches. } \\
\text { Costo } \$ 800 \text { por pax. } \\
\text { Grupo mínimo de } 6 \\
\text { personas. } \\
\end{array}$ \\
\hline \multirow{4}{*}{$\begin{array}{l}\text { WILDLIFE } \\
\text { AMAZON CÍA. } \\
\text { LTDA. }\end{array}$} & $\begin{array}{c}\text { Comunidad } \\
\text { Añango, } \\
\text { Ivdillama y } \\
\text { Centro de } \\
\text { Interpretación } \\
\text { Ambiental } \\
\text { Yaku } \\
\text { Kawsay } \\
\end{array}$ & $\begin{array}{l}\text { Grupo } \\
\text { étnico }\end{array}$ & $\begin{array}{c}\text { Turismo } \\
\text { comunitario }\end{array}$ & $\begin{array}{c}\text { Caminatas nocturnas. } \\
\text { Avistamiento de loros. } \\
\text { Senderos autoguiados. } \\
\text { Actividades culturales. } \\
\text { Recorridos en canoa. } \\
\text { Observación de reptiles. }\end{array}$ & $\begin{array}{c}\text { Lodge Añango } \\
\text { Laguna de Añango. }\end{array}$ & $\begin{array}{l}\text { Paquetes organizados } \\
\text { por operadoras. } \\
\text { Paquete de } 2 \text { días y } 1 \\
\text { noches. } \\
\text { Costo } \$ 320 \text { por pax. }\end{array}$ \\
\hline & $\begin{array}{c}\text { Tour } \\
\text { Shiripuno }\end{array}$ & $\begin{array}{l}\text { Grupo } \\
\text { étnico }\end{array}$ & $\begin{array}{c}\text { Turismo } \\
\text { comunitario }\end{array}$ & $\begin{array}{l}\text { Senderos autoguiados. } \\
\text { Actividades culturales. } \\
\text { Recorrido por los saladeros. } \\
\text { Recorrido por canoa. } \\
\text { Caminatas nocturnas. }\end{array}$ & $\begin{array}{c}\text { Comunidad Ñoñeno. } \\
\text { Comunidad Bameno. } \\
\text { Comunidad Boanamo. } \\
\text { Río Shiripuno. }\end{array}$ & $\begin{array}{l}\text { Paquetes organizados } \\
\text { por operadoras. } \\
\text { Paquete de } 6 \text { días y } 5 \\
\text { noches. } \\
\text { Costo } \$ 720 \text { por pax. }\end{array}$ \\
\hline & $\begin{array}{l}\text { Full day } \\
\text { Yasuni }\end{array}$ & $\begin{array}{c}\text { Naturaleza } \\
\text { y cultura }\end{array}$ & $\begin{array}{l}\text { Ecoturismo } \\
\text { y Turismo } \\
\text { comunitario }\end{array}$ & $\begin{array}{l}\text { Visita al saladero de loros. } \\
\text { Senderos autoguiados. } \\
\text { Actividades culturales. } \\
\text { Recorrido en } \\
\text { Visita a comunidades cercanas. }\end{array}$ & $\begin{array}{l}\text { Lodge Añango. } \\
\text { Saladero de loros. } \\
\text { Laguna de } \\
\text { Añango. }\end{array}$ & $\begin{array}{l}\text { Paquetes organizados } \\
\text { por operadoras. } \\
\text { Duración: } 1 \text { día } \\
\text { Costo } \$ 80 \text { por pax } \\
\text { Grupo mínimo de } 3 \\
\text { personas. }\end{array}$ \\
\hline & $\begin{array}{l}\text { Añango- } \\
\text { Jatuncocha- } \\
\text { Pañococha }\end{array}$ & $\begin{array}{c}\text { Grupo } \\
\text { étnico. } \\
\text { Naturaleza. }\end{array}$ & $\begin{array}{l}\text { Ecoturismo- } \\
\text { Turismo } \\
\text { comunitario }\end{array}$ & $\begin{array}{c}\text { Camping. } \\
\text { Senderismo } \\
\text { Actividades culturales. } \\
\text { Recorrido en canoa por la laguna. } \\
\text { Caminatas nocturnas. }\end{array}$ & $\begin{array}{c}\text { Lodge Añango. } \\
\text { Laguna Jatuncocha y } \\
\text { Pañococha }\end{array}$ & $\begin{array}{l}\text { Paquetes organizados } \\
\text { por operadoras. } \\
\text { Duración } 3 \text { días y } 2 \\
\text { noches. Costo } \$ 420 \text { por } \\
\text { pax. }\end{array}$ \\
\hline
\end{tabular}




\begin{tabular}{|c|c|c|c|c|c|c|}
\hline \multirow[t]{2}{*}{$\begin{array}{l}\text { AMAZON } \\
\text { TRAVEL } \\
\text { TOURIST }\end{array}$} & $\begin{array}{l}\text { Limoncocha- } \\
\text { Sumakallpa }\end{array}$ & $\begin{array}{c}\text { Grupo } \\
\text { étnico. } \\
\text { Naturaleza. }\end{array}$ & $\begin{array}{l}\text { Ecoturismo- } \\
\text { Turismo } \\
\text { comunitario }\end{array}$ & $\begin{array}{c}\text { Observación de monos. } \\
\text { Actividades culturales. } \\
\text { Caminata nocturna. } \\
\text { Bebida de guayusa. } \\
\text { Visita a la reserva biológica. } \\
\text { Sendero hasta llegar al cedro } \\
\text { gigante. } \\
\text { Observación del caimán negro. }\end{array}$ & $\begin{array}{l}\text { Centro de biodiversidad } \\
\text { y rescate “Sumakallpa”. } \\
\text { Reserva biológica } \\
\text { Limoncocha. } \\
\text { Laguna de Limoncocha }\end{array}$ & $\begin{array}{l}\text { Paquetes organizados } \\
\text { por operadoras. } \\
\text { Duración: } 2 \text { días y } 1 \\
\text { noche. } \\
\text { Costo } \$ 180 \text { por pax. } \\
\text { Grupo mínimo de } 3 \\
\text { personas. }\end{array}$ \\
\hline & $\begin{array}{c}\text { Centro de } \\
\text { Interpretacion } \\
\text { Yaku } \\
\text { Kawsay, } \\
\text { Indillama }\end{array}$ & $\begin{array}{c}\text { Grupo } \\
\text { étnico. } \\
\text { Naturaleza. }\end{array}$ & $\begin{array}{l}\text { Turismo } \\
\text { científico }\end{array}$ & $\begin{array}{c}\text { Recorrido por las cabañas de Centro } \\
\text { de interpretación. } \\
\text { Senderismo } \\
\text { Recorrido en quilla }\end{array}$ & $\begin{array}{c}\text { Centro de interpretación } \\
\text { Yaku Kawsay. }\end{array}$ & $\begin{array}{l}\text { Paquetes organizados } \\
\text { por operadoras. } \\
\text { Duración: } 1 \text { día } \\
\text { Costo } \$ 80 \text { por pax }\end{array}$ \\
\hline
\end{tabular}

Fuente: Grupo de investigaciónDemanda y competencia potencial 
Tabla $N^{\circ}$ 17: Demanda potencial para los próximos 5 años

\begin{tabular}{|c|c|c|c|}
\hline \multirow{2}{*}{ Año } & \multicolumn{2}{|c|}{ Demanda } & Demanda potencial \\
\cline { 2 - 3 } & Nacional 74\% & Extranjera 79\% & \\
\hline $\mathbf{2 0 1 3}$ & 1901 & 5776 & 7677 \\
\hline $\mathbf{2 0 1 4}$ & 2148 & 6527 & 8675 \\
\hline $\mathbf{2 0 1 5}$ & 2427 & 7375 & 9803 \\
\hline $\mathbf{2 0 1 6}$ & 2743 & 8334 & 11077 \\
\hline $\mathbf{2 0 1 7}$ & 3100 & 9418 & 12517 \\
\hline $\mathbf{2 0 1 8}$ & 3502 & 10642 & 14144 \\
\hline $\mathbf{2 0 1 9}$ & 3958 & 12025 & 15983 \\
\hline $\mathbf{2 0 2 0}$ & 4472 & 13589 & 18061 \\
\hline
\end{tabular}

Para el año 2016 habrá una demanda de 11077 turistas y para el 2020 se proyecta a 18061 turistas.

Para realizar el análisis de la oferta se tomó en consideración a Shiripuno Lodge debido a que es la principal competencia que tienen las comunidades y es el único existente en la zona de estudio. Mismo que tiene 2072 visitantes anuales en actividades vinculadas al turismo comunitario.

Tabla $N^{\circ}$ 18: Oferta potencial para los próximos 5 años.

\begin{tabular}{|c|c|}
\hline Año & Shiripuno Lodge \\
\hline $\mathbf{2 0 1 3}$ & 2072 \\
\hline $\mathbf{2 0 1 4}$ & 2341 \\
\hline $\mathbf{2 0 1 5}$ & 2645 \\
\hline $\mathbf{2 0 1 6}$ & 2989 \\
\hline $\mathbf{2 0 1 7}$ & 3378 \\
\hline $\mathbf{2 0 1 8}$ & 3817 \\
\hline $\mathbf{2 0 1 9}$ & 4313 \\
\hline $\mathbf{2 0 2 0}$ & 4874 \\
\hline
\end{tabular}

La oferta para el 2016 será de 2989 personas y para el 2020 habrá 4874 turistas.

\section{Demanda insatisfecha}

\begin{tabular}{|c|c|c|c|}
\hline Año & Demanda actual & Cantidad de la oferta & Demanda insatisfecha \\
\hline 2013 & 7677 & 2072 & 5605 \\
\hline 2014 & 8675 & 2341 & 6334 \\
\hline 2015 & 9803 & 2645 & 7158 \\
\hline 2016 & 11077 & 2989 & 8088 \\
\hline 2017 & 12517 & 3378 & 9139 \\
\hline 2018 & 14144 & 3817 & 10327 \\
\hline 2019 & 15983 & 4313 & 11670 \\
\hline 2020 & 18061 & 4874 & 13187 \\
\hline
\end{tabular}

Para el año 2016 la demanda insatisfecha es de 8088 personas y para el 2020 será de 13187. 


\section{Diseño técnico del producto}

El producto está estructurado en torno a al potencial turístico previamente identificado en las comunidades de Atahualpa, Nantip y Ñoñeno además de los resultados obtenidos en el estudio de mercado.

Paquete $\mathrm{N}^{\circ}$ 1: Atahualpa cultura viva

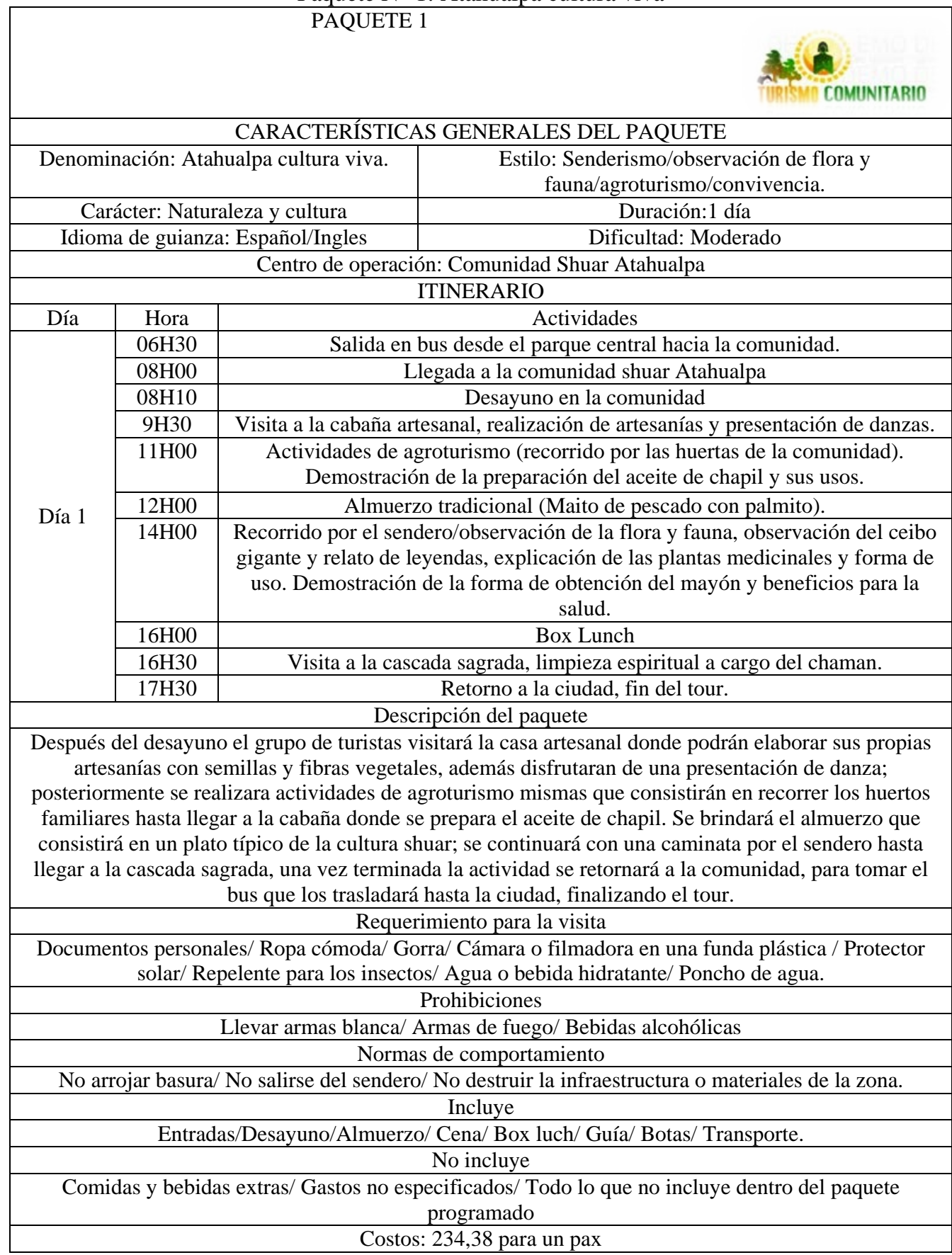


Paquete $\mathrm{N}^{\circ} 2$ : Encanto natural y cultural

\begin{tabular}{|c|c|c|c|}
\hline \multicolumn{4}{|c|}{ PAQUETE 2} \\
\hline \multicolumn{4}{|c|}{ CARACTERÍSTICAS GENERALES DEL PAQUETE } \\
\hline \multicolumn{3}{|c|}{ Denominación: Encanto natural y cultural } & $\begin{array}{l}\text { Estilo: Senderismo/observación de flora y fauna/ } \\
\text { convivencia con la comunidad/chamanismo/danza. }\end{array}$ \\
\hline \multicolumn{3}{|c|}{ Carácter: Naturaleza y cultura } & Duración:2 día \\
\hline \multirow{2}{*}{\multicolumn{3}{|c|}{$\begin{array}{r}\text { Idioma de guianza: Español/Ingles } \\
\text { Centro de opera }\end{array}$}} & Dificultad: Moderado \\
\hline & & & a: Comunidad Shuar Nantip \\
\hline \multicolumn{4}{|c|}{ ITINERARIO } \\
\hline Día & Hora & & Actividades \\
\hline \multirow[t]{11}{*}{ Día 1} & 07H30 & & Arribo a la comunidad Nantip \\
\hline & 07H40 & & Desayuno \\
\hline & 09H30 & Recorrido & quilla por el río Tiguano, observación de aves. \\
\hline & $10 \mathrm{H} 30$ & Caminata por el s & $\begin{array}{l}\text { lero, explicación de las plantas medicinales, relato de } \\
\text { leyendas. }\end{array}$ \\
\hline & $11 \mathrm{H} 30$ & Explicación y dem & ración del proceso de elaboración de la panela casera. \\
\hline & $12 \mathrm{H} 00$ & & Almuerzo (comida típica). \\
\hline & $14 \mathrm{H} 00$ & Demostración de la & Doración de artesanías y las trampas ancestrales de caza. \\
\hline & $16 \mathrm{H} 00$ & Convivencia con la & nunidad, presentación de danzas y música de la cultura. \\
\hline & $18 \mathrm{H} 00$ & Inst & r el campamento en el área de camping \\
\hline & $19 \mathrm{H} 00$ & & Cena \\
\hline & $20 \mathrm{H} 00$ & & ecorrido nocturno o noche cultural \\
\hline \multirow[t]{8}{*}{ Día 2} & $08 \mathrm{H} 00$ & & Desayuno \\
\hline & $09 \mathrm{H} 00$ & Avista & nto de animales silvestres en los saladeros \\
\hline & $10 \mathrm{H} 30$ & & Box lunch \\
\hline & $11 \mathrm{H} 00$ & & ráctica de pesca en el río Tiguano. \\
\hline & $12 \mathrm{H} 00$ & & Almuerzo \\
\hline & $14 \mathrm{H} 00$ & & ealización de juegos tradicionales \\
\hline & $15 \mathrm{H} 00$ & & Box lunch \\
\hline & $15 \mathrm{H} 30$ & Retor & a la ciudad Puerto Francisco de Orellana \\
\hline \multicolumn{4}{|c|}{ Descripción del paquete } \\
\hline \multicolumn{4}{|c|}{$\begin{array}{c}\text { Después del desayuno se realizará un recorrido en canoa por las aguas del río Tiguano para la } \\
\text { observación de aves y animales que salen a las orillas del río, luego nos internaremos en la selva a } \\
\text { emprender una caminata para un mayor contacto con la naturaleza, al llegar a la comunidad seremos } \\
\text { participes del proceso de elaboración de la panela casera, además disfrutaran de la presentación de } \\
\text { danzas típicas de la cultura. Al segundo día se observara algunas especies de animales en los saladeros, } \\
\text { se realizara pesca deportiva en la tarde el grupo de mujeres kallary les demostrará como elaborar } \\
\text { algunas artesanías y organizaran juegos tradicionales. Fin del tour. }\end{array}$} \\
\hline \multicolumn{4}{|c|}{ Requerimiento para la visita } \\
\hline \multicolumn{4}{|c|}{$\begin{array}{c}\text { Documentos personales/ Ropa cómoda/ Gorra/ Linterna/ Cámara/o filmadora en una funda plástica/ } \\
\text { Protector solar/ Repelente para los insectos/ Agua o bebida hidratante/ Poncho de agua/ carpa/ } \\
\text { sleeping. }\end{array}$} \\
\hline \multicolumn{4}{|c|}{ Prohibiciones } \\
\hline \multicolumn{4}{|c|}{ Llevar armas blanca/ Armas de fuego/ Bebidas alcohólicas } \\
\hline \multicolumn{4}{|c|}{ Normas de comportamiento } \\
\hline \multicolumn{4}{|c|}{$\begin{array}{l}\text { No arrojar basura/ No salirse del sendero/ No destruir la infraestructura o materiales de la zona/ No } \\
\text { recolectar especies vegetales o animales. }\end{array}$} \\
\hline \multicolumn{4}{|r|}{ Incluye } \\
\hline \multicolumn{4}{|c|}{ Entradas/ Desayuno/ Almuerzo/ Cena/ Box luch/ G } \\
\hline \multicolumn{4}{|c|}{ No incluye } \\
\hline & & Comidas y bebid & xtras/ Gastos no especificados. \\
\hline
\end{tabular}


Paquete $\mathrm{N}^{\circ}$ 3: Cultura en un rincón de la selva PAQUETE 3

\begin{tabular}{|c|c|c|c|}
\hline \multicolumn{4}{|c|}{ PAQUETE 3} \\
\hline \multicolumn{4}{|c|}{ CARACTERÍSTICAS GENERALES DEL PAQUETE } \\
\hline \multicolumn{3}{|c|}{$\begin{array}{l}\text { Denominación: Cultura en un rincón de la } \\
\text { selva }\end{array}$} & $\begin{array}{l}\text { Estilo: Recorrido en canoa a motor/observación de flora } \\
\text { y fauna/ convivencia con la comunidad/senderismo/ } \\
\text { trekking. }\end{array}$ \\
\hline \multicolumn{3}{|c|}{ Carácter: Naturaleza y cultura } & Duración:2 días y 1 noche \\
\hline \multicolumn{3}{|c|}{ Idioma de guianza: Español/Ingles } & Dificultad: Moderado \\
\hline \multicolumn{4}{|c|}{ Centro de operación: Comunidad Waorani Ñoñeno. } \\
\hline \multicolumn{4}{|c|}{ ITINERARIO } \\
\hline \multirow[t]{12}{*}{ Día } & Hora & & Actividades \\
\hline & $7 \mathrm{H00}$ & & slado a la comunidad waorani Ñoñeno \\
\hline & $10 \mathrm{H} 00$ & $\begin{aligned} & \\
\text { Pintado del ro } & \end{aligned}$ & $\begin{array}{l}\text { ecibimiento de la comunidad waorani. } \\
\text { ro de los visitantes a cargo de las mujeres waoranis. }\end{array}$ \\
\hline & $10 \mathrm{H} 30$ & Recorrido por la cor & $\begin{array}{l}\text { unidad Ñoñeno y explicación de la forma de construcción } \\
\text { de sus viviendas y formas de vida. }\end{array}$ \\
\hline & $12 \mathrm{H} 00$ & & Almuerzo típico \\
\hline & $14 \mathrm{H} 00$ & Visita a la laguna $\tilde{\Gamma}$ & $\begin{array}{l}\text { ñeno, avistamiento de aves y de tortugas charapas, toma } \\
\text { de fotografías. }\end{array}$ \\
\hline & $16 \mathrm{H} 00$ & & Box lunch \\
\hline & $16 \mathrm{H} 30$ & $\begin{array}{l}\text { Actividad recreaci } \\
\text { prender fuego }\end{array}$ & $\begin{array}{l}\text { nal, practica de cerbatanas, demostración de la forma de } \\
\text { n forma ancestral y tradicional, limpieza chamanica. }\end{array}$ \\
\hline & $17 \mathrm{H} 30$ & Natc & ión o pesca deportiva en el río Shiripuno. \\
\hline & $18 \mathrm{H} 30$ & & paración de las carpas en la comunidad. \\
\hline & $18 \mathrm{H} 45$ & & Cena \\
\hline & $20 \mathrm{H} 00$ & & che cultural (Fogata, danzas, música). \\
\hline \multirow[t]{7}{*}{2} & $8 \mathrm{H} 00$ & & Desayuno \\
\hline & $9 \mathrm{H} 00$ & $\begin{array}{r}\text { Recorrido por el rí } \\
\text { tortugas c }\end{array}$ & $\begin{array}{l}\text { Shiripuno, observación de las aves, monos, mariposas y } \\
\text { arapas. Relato de historias cuentos y creencias. }\end{array}$ \\
\hline & $10 \mathrm{H} 30$ & & Box lunch \\
\hline & $11 \mathrm{H} 00$ & $\begin{array}{l}\text { Recorrido por los } \\
\text { bosque húmedo an }\end{array}$ & $\begin{array}{l}\text { uertos familiares y por el sendero que conduce hacia el } \\
\text { zónico, demostración de las formas de orientación en la } \\
\text { selva y caza. }\end{array}$ \\
\hline & $12 \mathrm{H} 00$ & & Almuerzo típico \\
\hline & $14 \mathrm{H} 00$ & Toma de fotogr & fías con las familias waorani y compra de artesanías. \\
\hline & 14H30 & Arrib & a la ciudad Puerto Francisco de Orellana. \\
\hline \multicolumn{4}{|c|}{$\begin{array}{ll}\text { Descripción del paquete } \\
\end{array}$} \\
\hline \multicolumn{4}{|c|}{$\begin{array}{l}\text { El tour tendrá una duración de dos días para lo cual se han establecido varias actividades como pintado } \\
\text { de rostros, recorrido por la comunidad, observación de la flora y fauna, prácticas de juegos } \\
\text { tradicionales, demostración de algunas prácticas tradicionales, visita a la laguna y recorridos por la } \\
\text { comunidad, etc. Una vez concluido con el itinerario retornaremos a la ciudad concluyendo con el } \\
\text { tour. }\end{array}$} \\
\hline \multicolumn{4}{|c|}{ Requerimiento para la visita } \\
\hline \multirow{2}{*}{\multicolumn{4}{|c|}{$\begin{array}{c}\text { Documentos personales/ Ropa cómoda/ Gorra/ Cámara o filmadora en una funda plástica / Protector } \\
\text { solar/ Repelente para los insectos/ Agua o bebida hidratante/ Poncho de agua/ carpas/ slepping. } \\
\text { Prohibiciones }\end{array}$}} \\
\hline & & & \\
\hline \multicolumn{4}{|c|}{ Llevar armas blanca/ Armas de fuego/ Bebidas alcohólicas } \\
\hline \multicolumn{4}{|c|}{ Normas de comportamiento } \\
\hline & oasur & $\begin{array}{l}\text { sendero/ } \\
\text { lectar es }\end{array}$ & $\begin{array}{l}\text { o destruir la infraestructura o materiales de la } \\
\text { cies vegetales o animales. }\end{array}$ \\
\hline
\end{tabular}




\begin{tabular}{|c|}
\hline Incluye \\
\hline Entradas/ Desayuno/Almuerzo/Cena/ Box luch/ Guía/ Botas/ Transporte/Alojamiento. \\
\hline No incluye \\
\hline Comidas y bebidas extra/ Gastos no especificados/ Todo lo que no incluye dentro del paquete \\
programado \\
\hline Costos: 393,13 para un pax \\
\hline
\end{tabular}

\section{Conclusion}

Las comunidades de Atahualpa, Nantip y Ñoñeno del cantón Francisco de Orellana, disponen de diversos atractivos naturales y culturales con potencial para la práctica del turismo comunitario, mismo que alcanzan una jerarquía II, los cuales pueden ser aprovechados de forma sostenible.

Mediante el análisis de la demanda se determinó que la implementación de la ruta de turismo comunitario tiene un alto índice de aceptación en los turistas nacionales (74\%) y extranjeros (79\%), y las personas encuestadas estarían dispuestas a gastar de 100 hasta 250 dólares lo cual demuestra que existe una amplia aceptación para adquirir el producto turístico.

Las actividades por las cuales más se inclinaron los turistas encuestados con mayor porcentaje fue de observación de flora y fauna, convivencia con la comunidad seguido de demostración de plantas medicinales.

Para el diseño técnico del producto se tomó en cuenta las características de la demanda, las potencialidades turísticas identificadas y la infraestructura turística disponible en las comunidades, diseñando de esta forma tres paquetes turísticos.

\section{References:}

1. ANINP. (2013-2017). Agenda Nacional para la Igualdad de Naciovalidades y Pueblos. Quito-Ecuador Pp. 7.

2. Ávila, Herrero, Aguirre, Morera, Aguilar, Ruiz, .Giraldo. (2002). Turismo Sostenible. Madrid: IEPALA Pp. 119.

3. Azevedo, L. (2007). Ecoturismo indígena. Primera Edicion. QuitoEcuador:Abya-Yala Pp. 32-64.

4. Constitución de la República del Ecuador, 2. (2008). Montecristi: Asamblea nacional de la República del Ecuador Pp. 13.

5. Coordinación General de Estadistica e Investigación del Ministerio de Turismo del Ecuador. (2015). Indicadores de turismo febrero del 2015 . Recuperado el 13 de 07 de 2016, de http://www.quitoturismo.gob.ec/index.php/es/estadisticas/quito-encifras?download=425:mintur-boletin-febrero-2015 Pp. 6-11. 
6. Cobarcos, N. (2006). Promoción y ventas de servicios turísticos, comercialización de servicios turísticos. Primera Edición. España: Ideas Propias.

7. Crosby, A. (2009). Re-inventando el turismo rural: gestión y desarrollo (Primera ed.). Barcelona-España: Laertes S.A Pp. 17.

8. Gurría, M (2004). Introducción al turismo. México:Trillas Pp. 95.

9. Jaramillo, R. (2006). La hora del turismo. Bogota-Colombia: Norma Pp. 3.

10. Kekutt, E. (2014). Turismo: herramienta social. Buenos Aires: Dunken Pp. 55-56.

11. Ley de turismo. (2008). Registro oficial suplemento 733 de 27 de diciembre del 2002: última modificación 06 de mayo del 2008: estado vigente Pp. 1.

12. MINTUR. (2011-2014). Proyecto PLANDETUR. Recuperado el 17 de julio de 2016, de http://www.turismo.gob.ec/wpcontent/uploads/2015/04/proyecto_plandetur_2011_2014VERSION2 .pdf. Pp. 3.

13. PLANDETUR. (2020). Plan estratégico de desarrollo de turismo sostenible para Ecuador. Recuperado el 14 de Julio de 2016, de http://www.undp.org.ec/odm/planes/plandetur.pdf. Pp. 12.

14. Quesada, R. (2007). Elementos del turismo (Primera Edición.). Costa Rica: EUNED Pp. 8.

15. Reglamento para los Centros Turísticos Comunitarios. (2010). Acuerdo ministerial 16: registro oficial 154 de 19 marzo del 2010, estado vigente Pp. 1.

16. Ruiz, E., \& Solis, D. (2007). Turismo comunitario en Ecuador: desarrollo y sostenibilidad social (Primera Edición.). Quito-Ecuador: Abya-Yala Pp. 12-51.

17. Santana, C., \& Atiencia, M. (2014). Turismo comunitario: reflexiones. Recuperado el 17 de julio de 2016, de http://biblio.ecotec.edu.ec/revista/edicionespecial/TURISMO\%20CO MUNITARIO.pdf Pp. 71.

18. SENPLADES. (2013-2017). Secretaría Nacional de Planificación y Desarrollo - Plan Nacional de Desarrollo/ Plan Nacional para el Buen Vivir". 2013-2017 (Primera Edición.). Quito-Ecuador Pp. 14-309. 


\section{ANEXOS}

Anexo $N^{\circ}$ 1: Entrevista dirigida a turistas nacionales ESCUELA SUPERIOR POLITÉCNICADE CHIMBORAZO FACULTAD DE RECURSOS NATURALES CARRERA DE INGENIERÍA EN TURISMO SOSTENIBLE

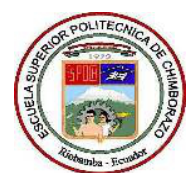

Objetivo: Recabar información relacionada con el estudio de factibilidad para la implementación de una Ruta de Turismo Comunitario para el cantón Francisco de Orellana, provincia de Orellana. Estimado turista solícito a usted muy comedidamente responder los siguientes ítems.

Marque con un (x) el ítem que corresponda.

1. Información general

Género: Masculino ( ) Femenino ( ) Edad: Estado civil

Procedencia:

2. ¿Con quién suele organizar sus viajes?

Solo ( ) Amigos ( ) Familiares ( ) Pareja ( )

3. ¿Cómo organiza sus viajes?

Agencias de viaje ( ) De forma independiente ( )

4. ¿ ¿Cuál es su motivo de viaje?

Turismo ( ) Trabajo ( ) Investigación ( ) Visita a familiares ( ) Salud ( ) Negocios ( ).

5. ¿Con qué frecuencia realiza actividades turísticas?

Cada 15 días ( ) Una vez al mes ( ) Una vez al año ( ) Feriados ( )

6. ¿Conoce alguna ruta turística dentro del cantón Francisco de Orellana?

Si: Cuál No

7. ¿Visitaría usted una ruta de turismo comunitario dentro del cantón Francisco de Orellana?

$\mathrm{Si}$

8. ¿Cuál de las siguientes actividades les gustaría realizar?

Caminata ( ) Observación de flora y fauna ( ) Medicina natural ( ) Chamanismo ( ) Compra de artesanías ( ) Danzas ( )

9. ¿Qué tipo de alimentación prefiere?

Típica ( ) Nacional ( ) Vegetariana ( ) Internacional ( )

10. Durante su visita ¿con qué servicios le gustaría contar?

Alimentación ( ) Hospedaje ( ) Transporte ( ) Guianza ( )

11. ¿Cuánto estaría dispuesto a gastar para visitar una ruta turística?

100-150 dólares ( ) 150-200 dólares ( )

200-250 dólares ( ) 250-300 dólares （）

12. ¿Qué medios de comunicación utiliza para informarse sobre actividades turísticas?

Guías/Folletos ( ) TV Local ( ) Internet ( ) Amigos/Familiares ( ) 
Anexo $N^{\circ}$ 2: Entrevistas para turistas internacionales ESCUELA SUPERIOR POLITÉCNICADE CHIMBORAZO FACULTAD DE RECURSOS NATURALES CARRERA DE INGENIERÍA EN TURISMO SOSTENIBLE

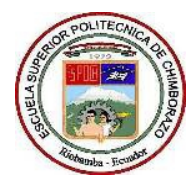

Objective: Collecting information relating to the feasibility study for implementing a Community Tourism Route. Dear tourist please answer the following quartier honestly

1. General information

Gender: Male ( ) Female ( ) Age:

2. ¿Who you usually travel with?

Civil status

Country:

Alone ( ) Friends ( ) Family ( ) Couple ( )

3. ¿How do you organize your trips?

Travel Agency ( ) Independent ( )

4. $¿$ What is the purpose if your trip.

Tourism ( ) Business ( ) Scientific researches ( ) Visit to families ( ) Health tourism

( ) Work ( ).

5. ¿How often do you perform tourist activities?

Every 15 days ( ) Once a month ( ) Once a year ( ) holidays ( )

6. ¿Do you know some tourist route inside of the Francisco de Orellana county?

Yes: Which One?

Not

7. $\dot{i}$ You would like to visit a touristic route inside of the Francisco de Orellana county? Yes Not

8. ¿Which of the followings tourist activities do you like to do?

Hiking ( ) Observation flora and fauna ( ) Natural medicine ( ) Shamanism ( ) handicrafts ( ) Dancing ( )

9. ¿ What kind of food you prefer?

Typical ( ) National ( ) Vegetarian ( ) International ( )

10. During you visit $\dot{i}$ What kind of service would you like to have?

Meals ( ) Accommodation ( ) Transportation ( ) Guiding ( )

11. $\dot{i}$ How much be willing to spend in a visit to touristic route that owns all the facilities before mentioned?

100-150 dollars ( ) 150-200 dollars （） 200-250 dollars （） 250-300 dollars ( )

12. ¿ Through what media would you like to reserve information about the route? Guides / Brochures ( ) Local TV ( ) 